\section{Development of a polarization imaging method to detect paraffin-embedded pathology tissues before applying other techniques}

\author{
Ouafa Sijilmassi1 1,2* | José Manuel López-Alonso² \\ María del Carmen Barrio Asensio ${ }^{1}$
}

${ }^{1}$ Department of Anatomy and Embryology, Faculty of Optics and Optometry, Universidad Complutense De Madrid, Madrid, Spain

${ }^{2}$ Department of Optics, Faculty of Optics and Optometry, Universidad Complutense De Madrid, Madrid, Spain

Ouafa Sijilmassi, Universidad

Complutense De Madrid, Faculty of Optics and Optometry, Department of Anatomy and Embryology, Calle de Arcos de Jalón, 118, 28037 Madrid, Spain.

Email: o.sijilmassi@ucm.es

\section{Funding information}

Banco Santander, Grant/Award Number: CT27/16-CT28/16; Ministerio de Economía y Competitividad, Grant/Award Number: TEC2013-40442; Ministerio de Sanidad, Servicios Sociales e Igualdad, Grant/Award Number: PI06/0184 PS09/01762; Universidad Complutense de Madrid

\section{*Correspondence}

\begin{abstract}
The present article describes the development of a technique, applied to paraffinembedded tissues, which uses three different wavelengths of monochromatic light $(\lambda 1=445 \mathrm{~nm}, \lambda 2=540 \mathrm{~nm}$ and $\lambda 3=$ $660 \mathrm{~nm}$ ) for the measures of the degree of polarization, degree of linear polarization,
\end{abstract}

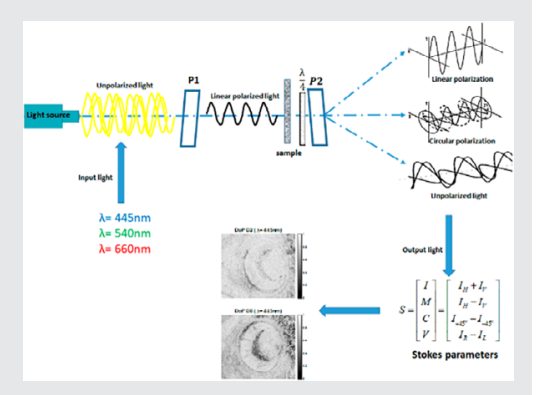
degree of circular polarization and birefringence, all obtained from measurements of Stokes parameters by using polarized light. The goal of this study was to detect changes in developing embryonic mouse eye when pregnant mice fed diets without folic acid for variable periods compared with a healthy control group. We present a biomedical diagnostic technique based on polarized light detection applied to paraffin-embedded tissues to visualize the structural damage to aid us in the diagnosis before applying other techniques. Through this method, we can visualize and identify which parts of the tissue were altered with respect to the control group.

\section{KE Y W O R D S}

biomedical optics, eye, imaging, polarization, Stokes parameters, tissue optics

\section{1 | INTRODUCTION}

polarimetry or Stokes polarimetry. It is important to note that Jones matrix polarimetry is used to measure the polarization-altering properties of the tissue and works with the amplitude of the beam of light applied to full polarized light. Whereas Stokes polarimetry is used to measure the polarization state of light in general and works with measurements of the intensity of the beam of light under test. ${ }^{[4,5]}$

This article focuses on the use of the change in the polarization state of a linearly polarized incident beam to study changes in embryonic ocular tissues. Embryos were born to mothers fed with a control or folic acid deficient
In mathematical linguistics, the different states of polarized light can be expressed using Mueller matrix 
1 (FAD) diet (for 2 and 8 weeks). Folic acid (FA) is essen2 tial for development since its intake in the first months of 3 gestation reduces the risk of congenital malformations in 4 the central nervous system caused by defective closure of 5 the neural tube. ${ }^{[6]}$ More recently, the important role of 6 FA for the correct development of many structures has 7 been seen,${ }^{[7,8]}$ including the eye. ${ }^{[9]}$ In general, the tradi8 tional methods to detect pathological tissues embedded 9 in paraffin are the staining methods used in anatomic 10 pathology such as Hematoxylin-Eosin which is the most 11 used, Mallory staining technique, as well as special tech12 niques in histopathology like Masson's trichromic 13 staining or histochemical techniques such as periodic 14 acid Schiff (PAS), among others. ${ }^{[10-12]}$

Polarized light has been used extensively for the study of tissue structures and pathologies (polarization microscopy) as well as to study its changes when the light passes through the tissue, ${ }^{[13,14]}$ given that the state of light polarization is very sensitive to the structural and scattering properties of tissue. Therefore, it is important to have a model and subsequent treatment of the data in order to extract relevant information about the tissue. This can be encoded in the spatial organization of the degree of depolarization and Stokes parameters ${ }^{[15]}$ or in the change that a specific state of polarization of the incident light undergoes (normally linear or circular polarized light) that makes it easy to relate these changes with tissue structures. ${ }^{[16]}$ For this reason, the main purpose of this article is to present a new method for the analysis of paraffin-embedded tissues before any staining can be done and without deparaffinization. This technique has been applied to visualize the structural damage in the tissue before marking to facilitate diagnosis. Another important novelty is the use of principal component analysis (PCA), a multivariate statistical method, to study the spatial distribution of the degree of the depolarizationinduced.

\section{2 | EXPERIMENTAL METHOD AND SAMPLES}

\subsection{Stokes vector parameter}

All four Stokes parameters (I, Q, U, V) can be measured by performing six intensity measurements $\left(\mathrm{I}_{0^{\circ}}, \mathrm{I}_{90^{\circ}}, \mathrm{I}_{45^{\circ}}\right.$, $\mathrm{I}_{135^{\circ}}, \mathrm{I}_{\mathrm{R}}$ and $\mathrm{I}_{\mathrm{L}}$ ) through a polarizer (linear or circular). ${ }^{[17]} \mathrm{I}$, represents the total intensity of light, Q and $U$ representing the linear polarization components and $\mathrm{V}$ represents the circularly polarized component. In this way, any change of polarization state of a light beam can be expressed as a 4-dimensional vector, the Stokes vector, as:

$$
S=\left[\begin{array}{c}
\mathrm{I} \\
\mathrm{Q} \\
\mathrm{U} \\
\mathrm{V}
\end{array}\right]=\left[\begin{array}{c}
\mathrm{I}_{0^{\circ}}+\mathrm{I}_{90^{\circ}} \\
\mathrm{I}_{0^{\circ}}-\mathrm{I}_{90^{\circ}} \\
\mathrm{I}_{45^{\circ}}-\mathrm{I}_{135^{\circ}} \\
\mathrm{I}_{\mathrm{R}}-\mathrm{I}_{\mathrm{L}}
\end{array}\right],
$$

54

55

56

57

where subscripts on I are the intensities at $0^{\circ}, 90^{\circ}$, $45^{\circ}, 135^{\circ}, \mathrm{I}_{\mathrm{R}}$ and $\mathrm{I}_{\mathrm{L}}$ states, measured with a horizontally linear analyzer, a vertically linear analyzer, a $45^{\circ}$ linear analyzer, a $135^{\circ}$ linear analyzer, a right circular analyzer, and a left circular analyzer, respectively.

The degree of polarization (DoP), degree of linear polarization (DoLP), degree of circular polarization (DoCP) and phase retardance $(\Delta \varepsilon)$ are given in terms of Stokes parameters, as ${ }^{[17,18] \text { : }}$

$$
\begin{gathered}
\mathrm{DoP}=\frac{\sqrt{\mathrm{Q}^{2}+\mathrm{U}^{2}+\mathrm{V}^{2}}}{\mathrm{I}} . \\
\mathrm{DoLP}=\frac{\sqrt{\mathrm{Q}^{2}+\mathrm{U}^{2}}}{\mathrm{I}} . \\
\operatorname{DoCP}=\frac{\mathrm{V}}{\mathrm{I}} . \\
\Delta \varepsilon=\tan ^{-1}\left(\frac{\mathrm{V}}{\sqrt{\mathrm{Q}^{2}+\mathrm{U}^{2}}}\right) .
\end{gathered}
$$

It must be noted that the DoP is unity if the light is totally polarized, and for completely unpolarised light, DoP is zero. On the other hand, the DoLP describes the fraction of the light that is linear polarized; DoLP is 0 if the light is not linear polarized light and 1 for perfectly linearly polarized light. Finally, DoCP describes the fraction of light that is circularly polarized. In case of the incident light is linearly polarized, this value is an indicator of the presence of birefringence in the medium; DoCP values are between 0 and 1 . Retardance $(\Delta \varepsilon)$ is the difference in phase shift an object introduces between its two orthogonal linear polarization states. ${ }^{[19]}$ When a birefringent sample is illuminated, the linearly polarized incident light is split into two components, extraordinary ray (refractive index, $\mathrm{n}_{0}$ ) and ordinary ray (refractive index, $\mathrm{n}_{\mathrm{e}}$ ). We will calculate the acquired birefringence $\Delta n=n_{0}-n_{\mathrm{e}}$, taking into account the following equation:

$$
\Delta \varepsilon=\frac{2 \pi}{\lambda}\left(n_{0}-n_{\mathrm{e}}\right) \mathrm{d} \Rightarrow \Delta n=n_{0}-n_{\mathrm{e}}=\frac{\lambda \cdot \Delta \varepsilon}{2 \pi \cdot \mathrm{d}},
$$

where $d$, is the thickness of the sample $(5 \mu \mathrm{m}), \lambda$ is the wavelength of the incident light and $\Delta \varepsilon$ is the phase 
retardation we had previously calculated for each of the three wavelengths.

\section{2 | Polarization imaging system}

By way of illustration, a schematic of the experimental polarimetry system used in the present study to measure the DoP in embryonic eye tissue samples using Stokes vectors to describe the polarization content of light exiting the sample is shown in Figure 1.

Tunable Light Source (TLS) 25C TLS was used as a light source, TLS-25C is optimized for the visible spectrum 360 to $1000 \mathrm{~nm}$. In the present work, Stokes parameter images at three different wavelengths of monochromatic light: $\lambda 1=445 \mathrm{~nm}, \lambda 2=540 \mathrm{~nm}$ and $\lambda 3=660 \mathrm{~nm}$, were reconstructed. The light beam passes first through an achromatic doublet (L1) to collimate the light; the emerging light is polarized along the vertical direction by the first linear polarizer (P1). Linearly polarized light at a wavelength impinges upon the eye tissue and passes through a quarterwave retarder (oriented at either $+45^{\circ}$ or $-45^{\circ}$ with respect to P1) and then through an analyzer P2. The light intensity emerging from $\mathrm{P} 2$ is collected and focused on two lenses $(\mathrm{L} 2, \mathrm{f}=50 \mathrm{~mm})$ and $(\mathrm{L} 3, \mathrm{f}=400 \mathrm{~mm})$. Finally, the image is recorded by an Imaging Source DFK21AF04 CCD Camera. This camera uses a 0.3 megapixel CCD image sensor capable of a resolution of $640 \times 480$ pixels, 1/4-inch, and pixel size H: $5.6 \mu \mathrm{m}$, V: $5.6 \mu \mathrm{m}$. A computer connected to the camera collects and analyzes the images.

Once the system is calibrated, the six polarimetric images in transmission $\left(\mathrm{I}_{0^{\circ}}\left(P_{1} \| P_{2}\right), \mathrm{I}_{90^{\circ}}\left(P_{1} \perp P_{2}\right), \mathrm{I}_{\mathrm{R}}\right.$ [quarter-wave retarder oriented at $+45^{\circ}$ with respect to $\mathrm{P} 1$ ] and $\mathrm{I}_{\mathrm{L}}$ [quarter-wave retarder oriented at $-45^{\circ}$ with respect to $\mathrm{P} 1], \mathrm{I}_{45^{\circ}}$ [P2 is oriented at $+45^{\circ}$ with respect to $\mathrm{P} 1], \mathrm{I}_{135^{\circ}}$ [P2 is oriented at $-45^{\circ}$ with respect to $\left.\left.\mathrm{P} 1\right]\right)$ for each eye at three different wavelengths of monochromatic light, were acquired. Afterwards, we have developed a series of scripts in MATLAB (MathWorks, R2018b) ${ }^{[20]}$ to estimate, over each image pixel-by-pixel, the four Stokes parameters (I, Q, U, V), as well as calculate the maps of the DoP, DoLP and DoCP, which can be calculated from the Stokes parameters employing the Equations (2),(3) and (4).

\section{3 | Samples}

To test the effect of maternal FAD on eye embryonic development, female C57/BL/6 J mice (Harlan Laboratories, Barcelona, Spain) were grouped in different diets.

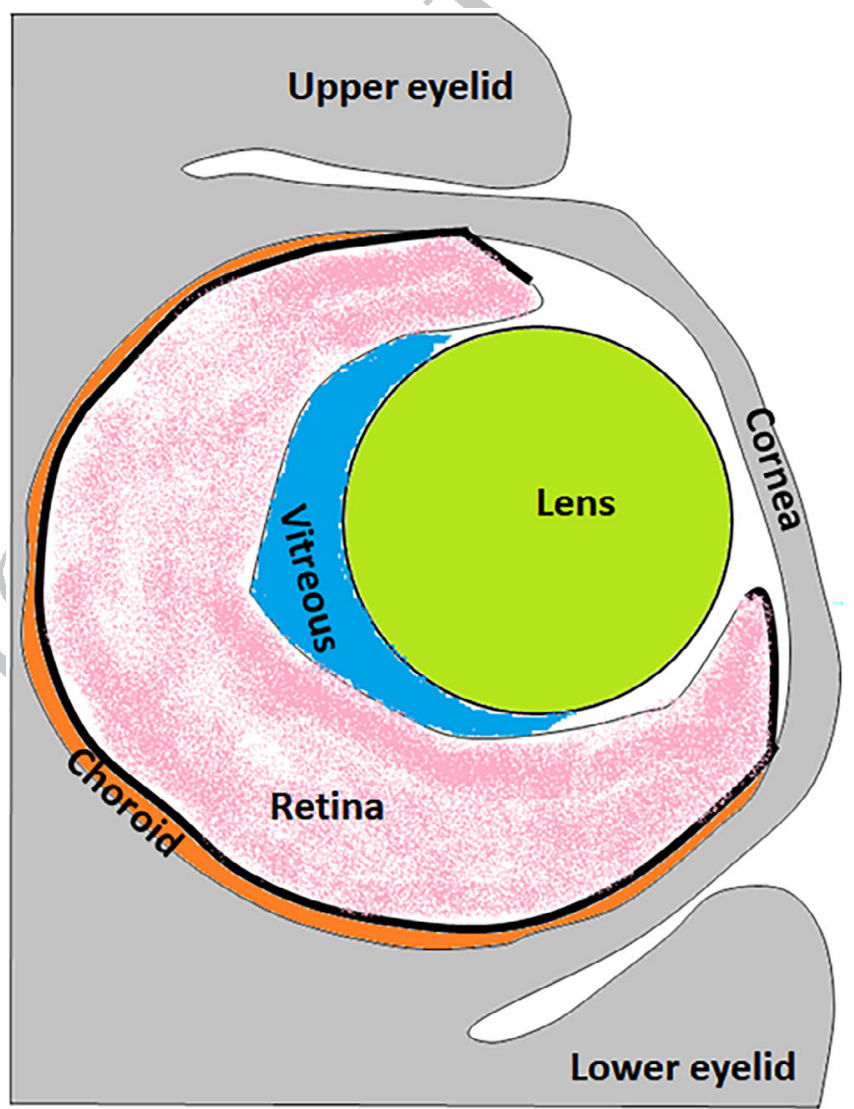

F I G U RE 2 Schematic representation of an embryonic eye showing its main components
FI G URE 1 Schematic illustration of the experimental setup used to measure the Stokes parameters to estimate the degree of polarization: L1: collimating lens, L2 and L3: converging lenses with focal lengths $\mathrm{f} 2=50 \mathrm{~mm}$ and $\mathrm{f} 3=400 \mathrm{~mm}$, P1: Linear polarizer, $\left(\frac{\lambda}{4}\right)$ : quarter- wave plate, and P2: the second polarizer (the analyzer) 
19
Mice were housed in rooms and were maintained in a temperature of $\left(22 \pm 2^{\circ} \mathrm{C}\right)$, relative humidity, and under a 12 hour light/dark cycle with free access to food and water at the animal care unit of the Facultad de Medicina of the Universidad Complutense de Madrid. All mice were cared for following the Guidelines of the Animal Experimentation Committee of the Universidad Complutense of Madrid.

The female mice were divided into three groups:

Control group: female mice were fed normal FA diet (SAFE A04/A03 Harlan) containing the recommended amount of FA for rodents, $2 \mathrm{mg} / \mathrm{kg}$ diet.

Group D2: female mice were fed a FA-Deficient diet (FAD) $\quad\left(\begin{array}{lllll}0 & \mathrm{mg} / \mathrm{kg} & \operatorname{diet} & +1 \% & \text { succinylsulfathiazole }\end{array}\right.$ [to prevent folate production by intestinal flora]), from the day after mating until gestational day 14.5 (E14.5).

Group D8: female mice were fed a FAD diet $(0 \mathrm{mg} / \mathrm{kg}$ diet $+1 \%$ succinylsulfathiazole) for a period of 8 weeks:
6 weeks before mating and through 2 weeks during pregnancy. ${ }^{[21]}$ At E14.5, mice were sacrificed and the embryos were collected.

Heads of embryos were fixed in buffered formaldehyde solution and dehydrated before being embedded in paraffin. Sections were cut at a thickness of $5-\mu \mathrm{m}$ on a rotary microtome Leica RM2265. Finally, the sections were deposited on glass microscope slides.

In this work, we have evaluated a total of 30 embryonic eyes (10 in each group: control, D2, and D8).

\section{3 | RESULTS AND DISCUSSION}

Before proceeding with the main results, it is important to describe the different part that forms the eyeball to help the reader visualize and interpret the maps of the DoP, DoLP and DoCP. For this reason, the principal

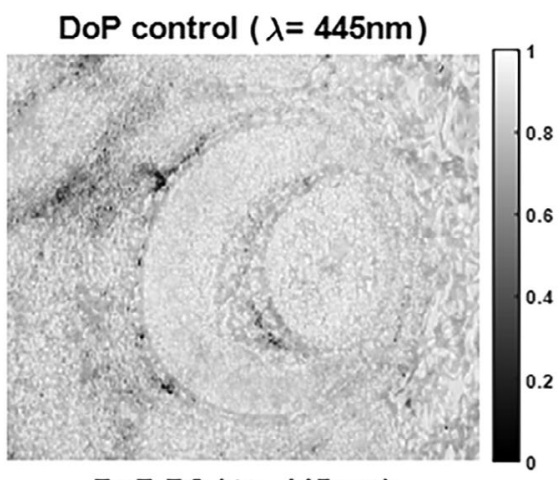

$\operatorname{DoP} \mathrm{D} 2(\lambda=445 \mathrm{~nm})$

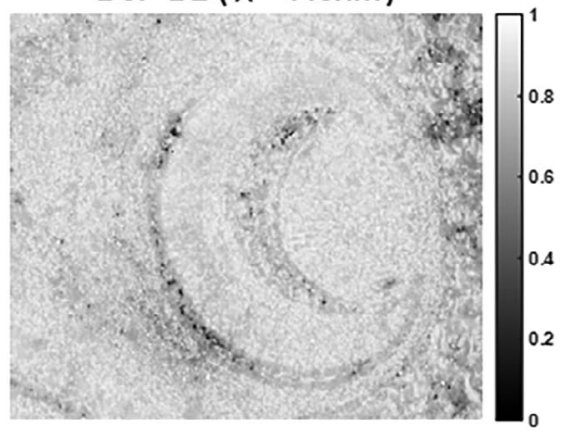

DoP D8 $(\lambda=445 \mathrm{~nm})$

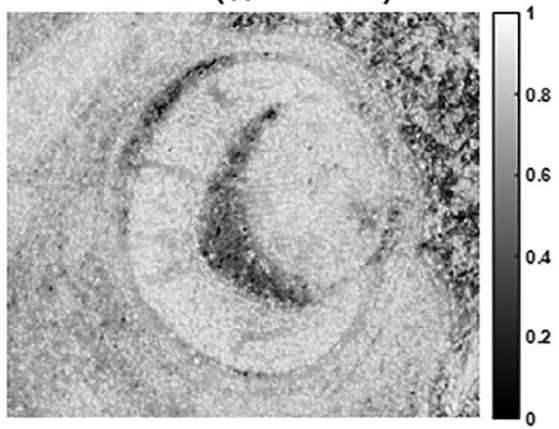

\section{DoP control $(\lambda=540 \mathrm{~nm})$}

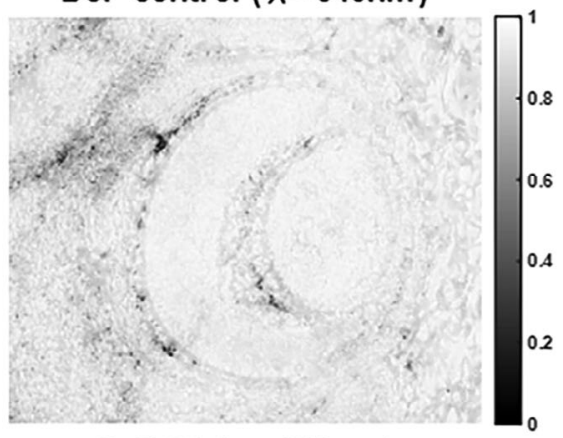

DoP D2 $(\lambda=540 \mathrm{~nm})$

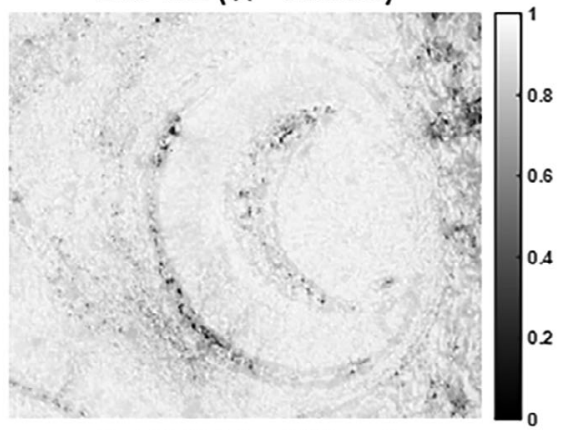

DoP D8 $(\lambda=540 \mathrm{~nm})$

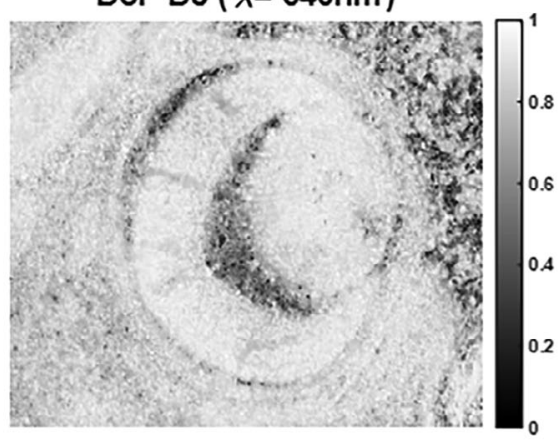

\section{DoP control $(\lambda=660 \mathrm{~nm})$}

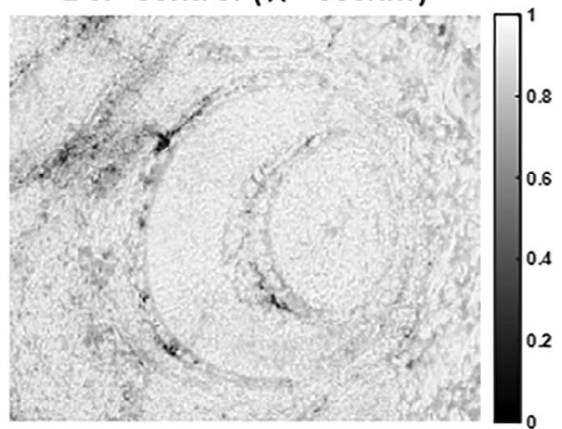

$\operatorname{DoP} \mathrm{D} 2(\lambda=660 \mathrm{~nm})$

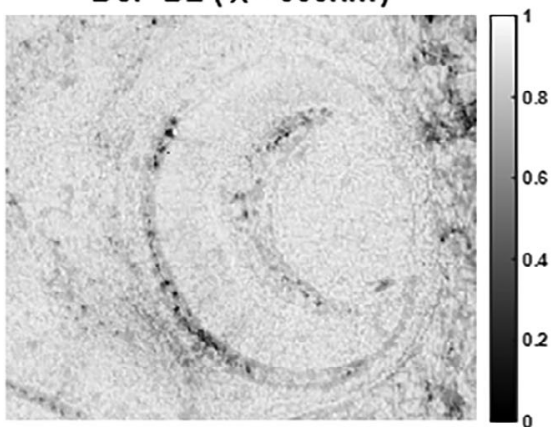

$\operatorname{DoP} D 8(\lambda=660 \mathrm{~nm})$

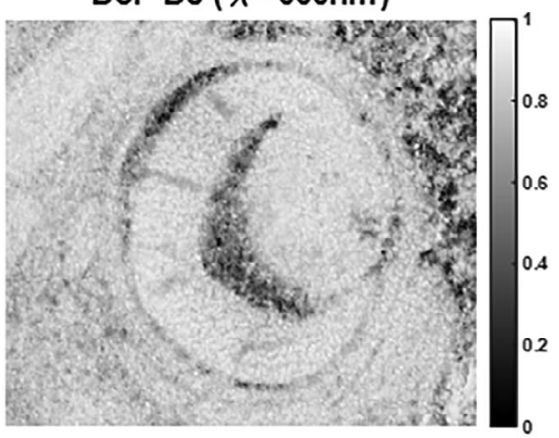

54 55

F I G U RE 3 Degree of polarization (DoP) polarization degree maps for the three sample groups (control, D2 and D8). Maps are obtained illuminating the eye tissues with three different wavelengths: 445,540 and $660 \mathrm{~nm}$ 
DoLP control ( $\lambda=445 \mathrm{~nm})$

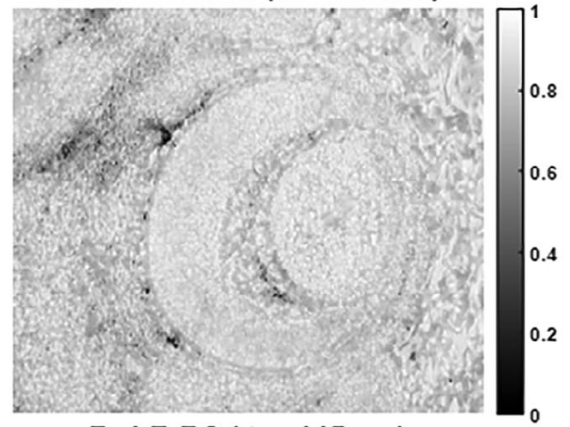

DoLP D2 $(\lambda=445 \mathrm{~nm})$

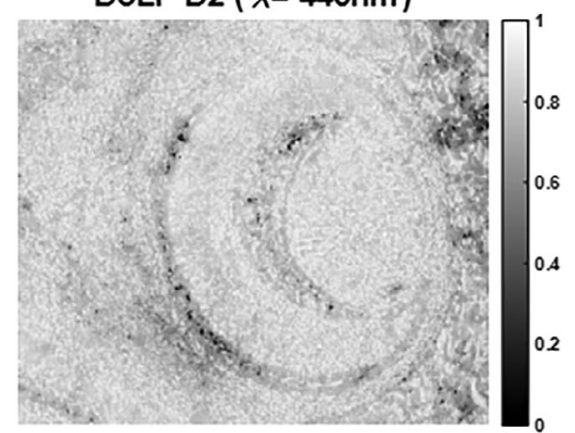

DoLP D8 $(\lambda=445 \mathrm{~nm})$

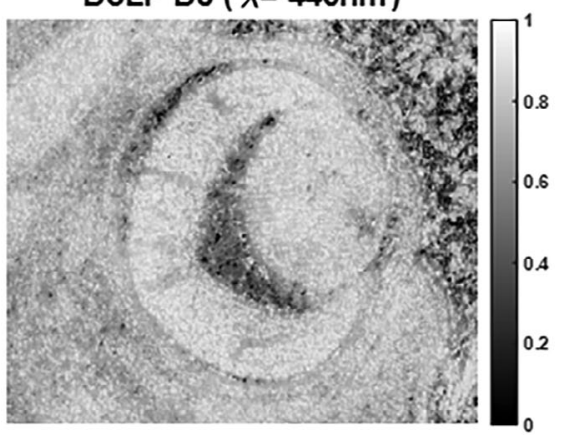

DoLP control ( $\lambda=540 \mathrm{~nm})$

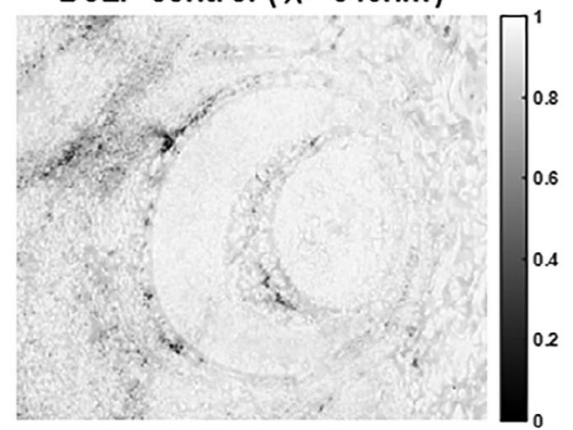

DoLP D2 $(\lambda=540 \mathrm{~nm})$

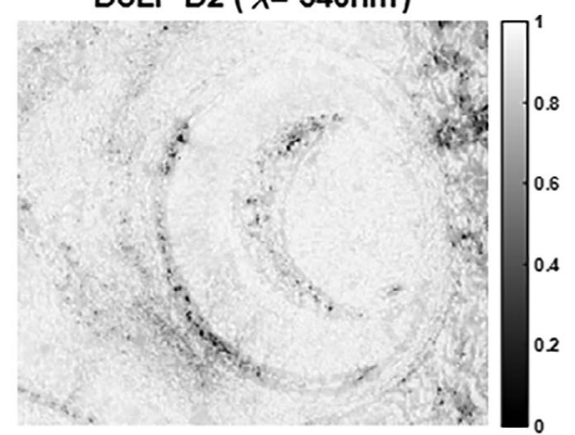

DoLP D8 $(\lambda=540 \mathrm{~nm})$

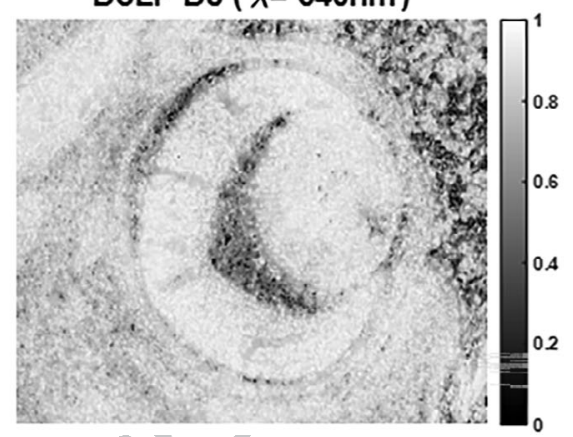

DoLP control ( $\lambda=660 \mathrm{~nm}$ )

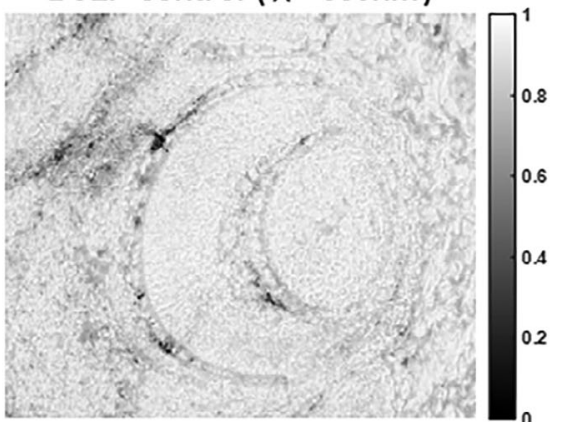

DoLP D2 $(\lambda=660 \mathrm{~nm})$

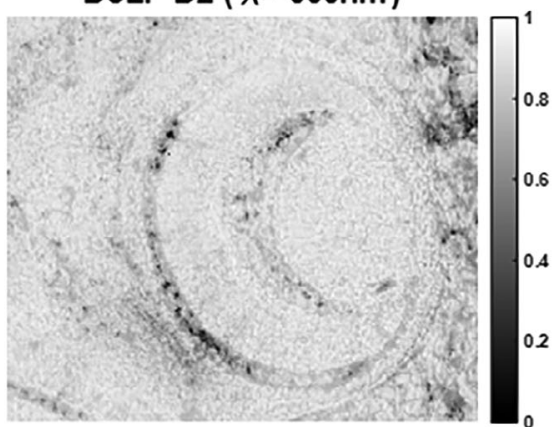

DoLP D8 $(\lambda=660 \mathrm{~nm})$

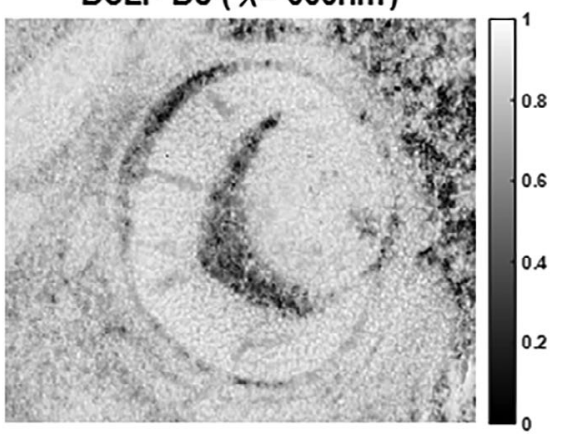

F I G U R E 4 Degree of linear polarization (DoLP) polarization degree maps for the three sample groups (control, D2 and D8). Maps are obtained illuminating the eye tissues with three different wavelengths: 445,540 and $660 \mathrm{~nm}$

36 components (PCs) of mouse embryonic eye that will 2 appear in this article are illustrated in Figure 2.

38 Six intensity images were taken and processed to Q5 39 acquire the degree of total polarization (DoP), DoLP and 40 DoCP image-maps for each eye and wavelength. The following figures (Figures 3, 4 and 5) represent the DoP, DoLP and DoCP image-maps, respectively. Each figure includes an example from the control (1st row), D2 (2nd row) and D8 (3rd row), illuminated with three different wavelengths: $\lambda 1=445 \mathrm{~nm}$ (1st column), $\lambda 2=540 \mathrm{~nm}$ ( 2 nd column) and $\lambda 3=660 \mathrm{~nm}$ ( 3 rd column).

Qualitatively, nearly the same spatial distribution results were observed for the DoP (Figure 3), as well as the DoLP (Figure 4). As the DoP or DoLP decreases from 1 to 0 , their maps at each of the three wavelengths show that depolarization of polarized light was much higher for samples with maternal FAD diet (D2 and D8) than the control group, especially in the choroid and vitreous.
Although in the case of D8 depolarization covers a wider area in both structures. Likewise, as seen in Figures 3 and 4, some zones of the lens and retina show higher depolarization in the D8 group compared to the control group.

On the other hand, the DoCP image-maps, shown in Figure 5, indicate that when linearly polarized light strikes the tissues of D2 and D8 groups, their state of polarization changes and becomes circularly or elliptically polarized light. This fact is clearly seen in the vitreous and choroid, and we can also see it in the retina, lens, cornea, eyelids among other regions.

In general, the incident polarization state of a light beam is changed on interaction with a sample. Indeed, the linearly polarized incident light can change its state to circular or elliptical due to birefringence or lose its DoP due to scattering phenomena. ${ }^{[22]}$ Given these points, we can extract the information about the structure of
89 


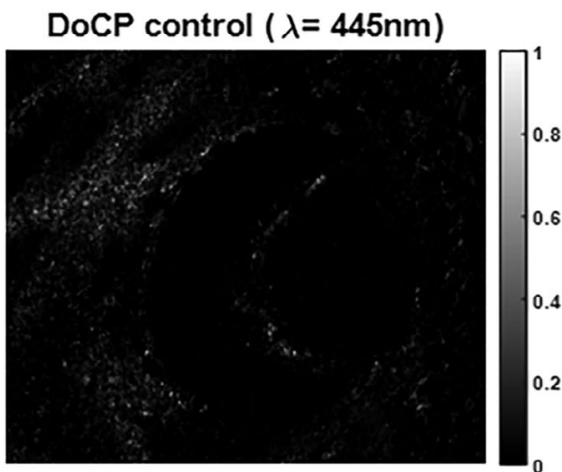

DoCP D2 $(\lambda=445 \mathrm{~nm})$

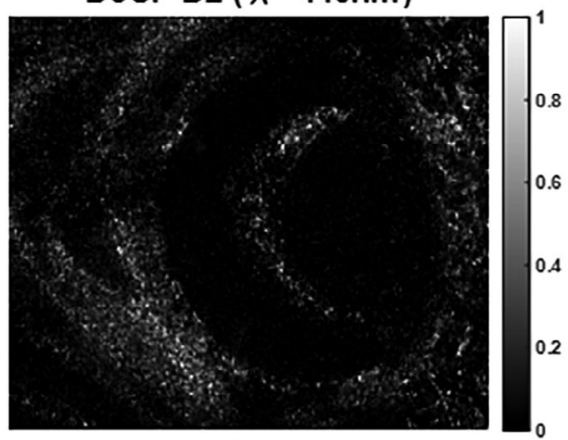

DoCP D8 $(\lambda=445 \mathrm{~nm})$

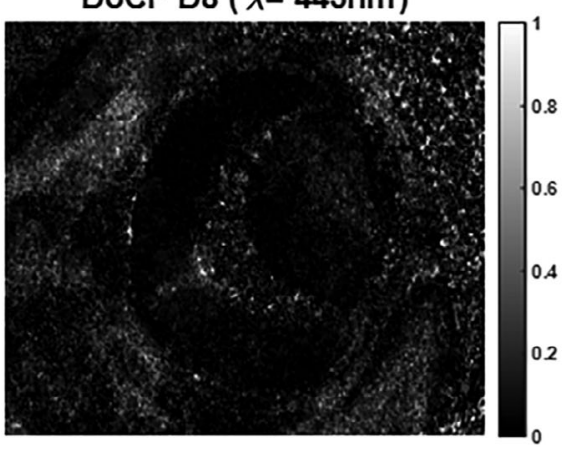

DoCP control $(\lambda=540 \mathrm{~nm})$

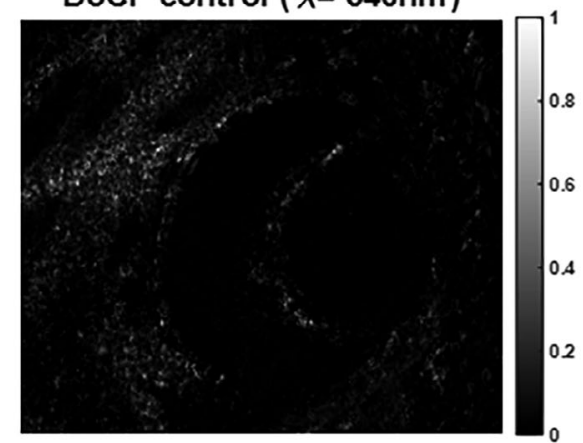

DoCP D2 $(\lambda=540 \mathrm{~nm})$

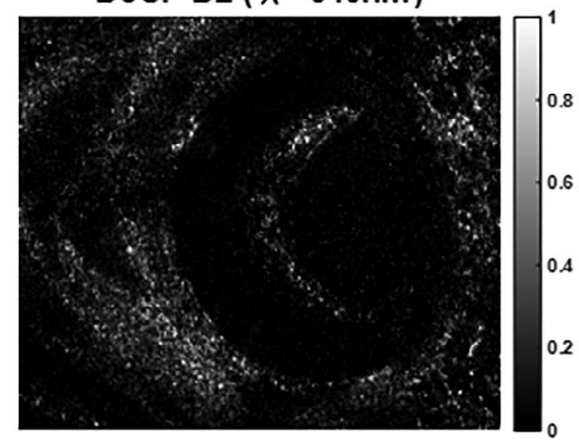

DoCP D8 $(\lambda=540 \mathrm{~nm})$

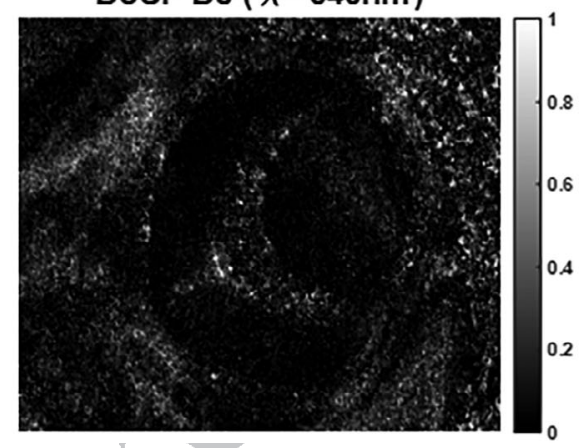

DoCP control $(\lambda=660 \mathrm{~nm})$

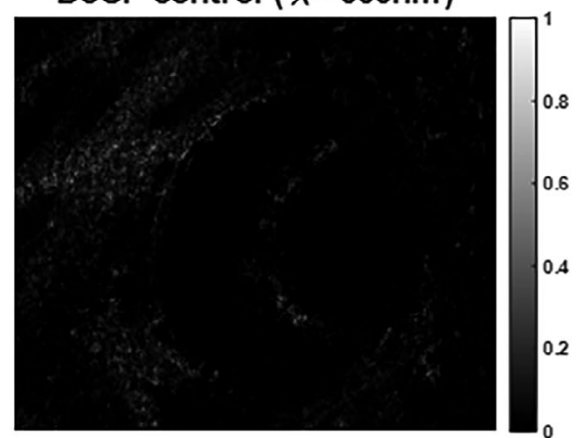

$\operatorname{DoCP} \mathrm{D} 2(\lambda=660 \mathrm{~nm})$

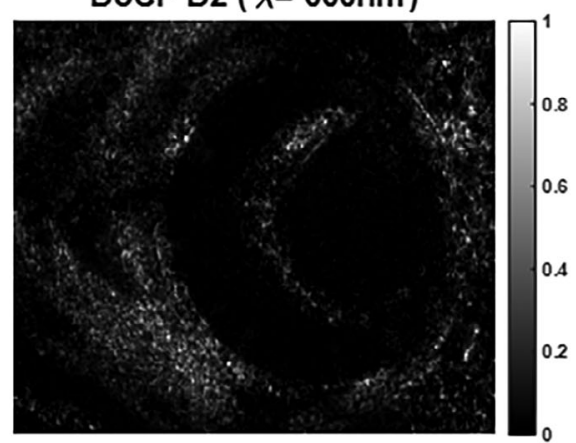

$\operatorname{DoCP} \mathrm{D} 8(\lambda=660 \mathrm{~nm})$

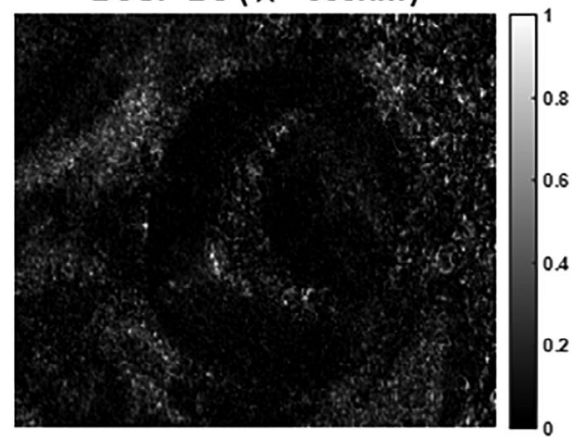

F I G U RE 5 Degree of circular polarization (DoCP) polarization degree maps for the three sample groups (control, D2 and D8). Maps are obtained illuminating the eye tissues with three different wavelengths: 445, 540 and $660 \mathrm{~nm}$

tissues and cell ensembles from the registered depolarization degree of initially polarized light, the transformed state of polarization, or the appearance of a polarized component in the scattered light. ${ }^{[3]}$ It is known that pathological processes are characterized by the changes of scattering and birefringence properties of tissues. ${ }^{[23]}$ According to the results shown in Figure 5, a birefringence effect acquired when mouse females were subjected to a diet lacking in FA, could has been induced.
Figure 6 shows the image-maps of some tissue's birefringence, measured at three wavelengths $(\lambda 1=445 \mathrm{~nm}$, $\lambda 2=540 \mathrm{~nm}$ and $\lambda 3=660 \mathrm{~nm}$ ). With a birefringence value in the order of $\Delta n=n_{0}-n_{\mathrm{e}}=5 \cdot 10^{-3}$, D2 and D8 groups show a clear increase in birefringence compared with the control group. This birefringence increases especially in D8 group into the following structures: lens, retina, embryonic blood vessels present in the vitreous (near the lens and retina), eyelids and choroid.
There are several diseases and disorders related to microstructural alteration or damage in the biological tissues. ${ }^{[24,25]}$ Microstructural alterations, such as changes in extracellular matrix (ECM) content and organization, ${ }^{[26,}$ ${ }^{27]}$ modifications in the fiber direction, ${ }^{[25]}$ or perhaps cellular orientations can lead to a change of birefringence. Imaging polarimetry is one of the most used methods to localize these microstructural disorders. ${ }^{[26]}$

In previous studies, we have observed that maternal dietary FAD alters the expression of collagen IV and laminin-1 into the lens and retina, and also reveals disorganization of fibers/cells orientation. ${ }^{\text {[28, 29] }}$

The present study shows for the first time that maternal dietary FAD also contributes to an alteration of the birefringence within eye tissues. Moreover, changes in ECM component proteins expression or its abnormal alignment within the structures could be other possible causes of eye tissues birefringence alteration. 

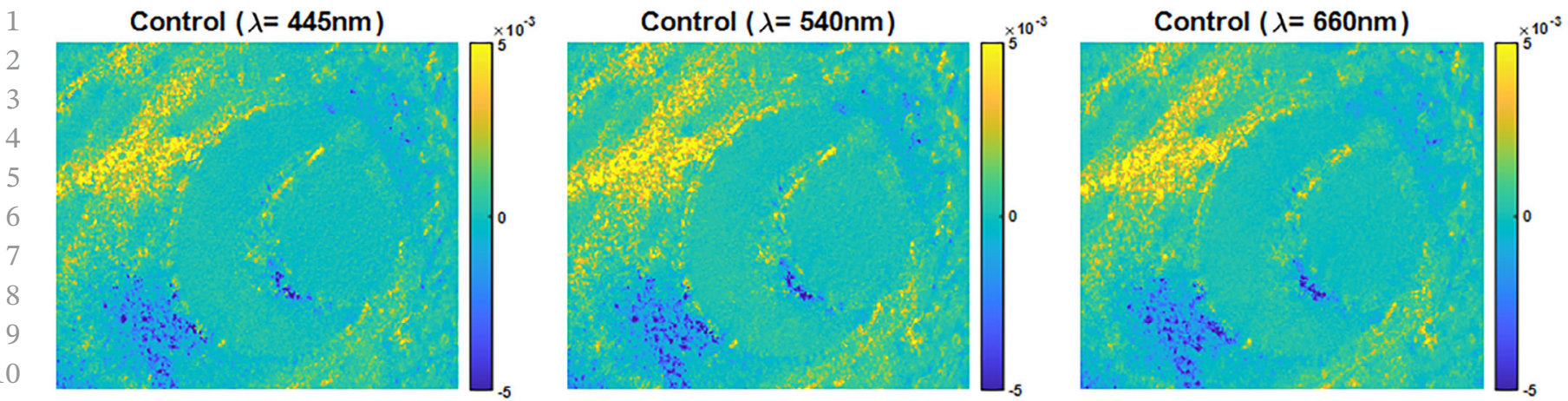

54
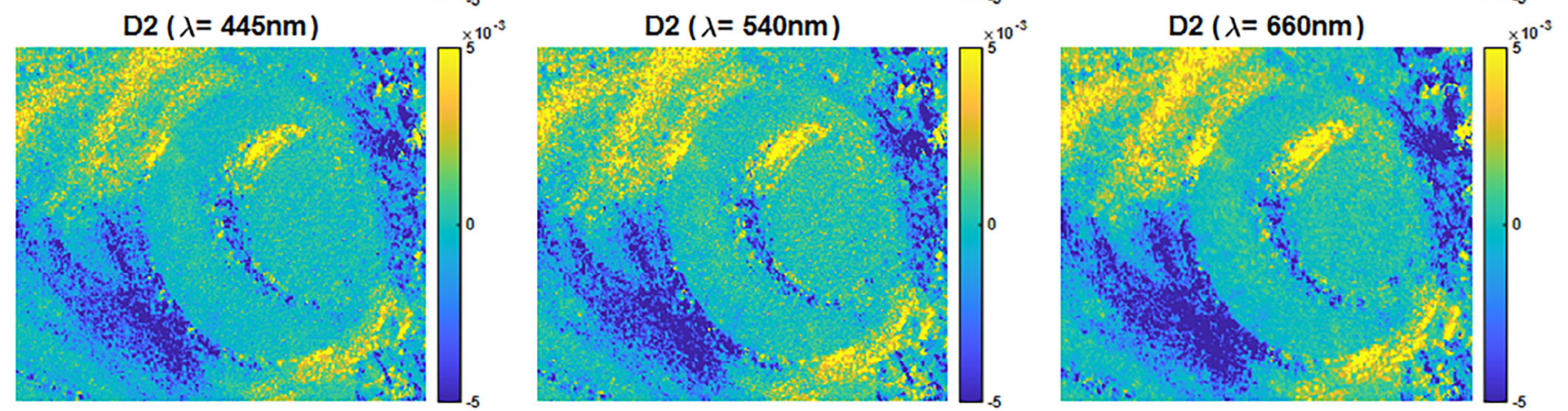

64
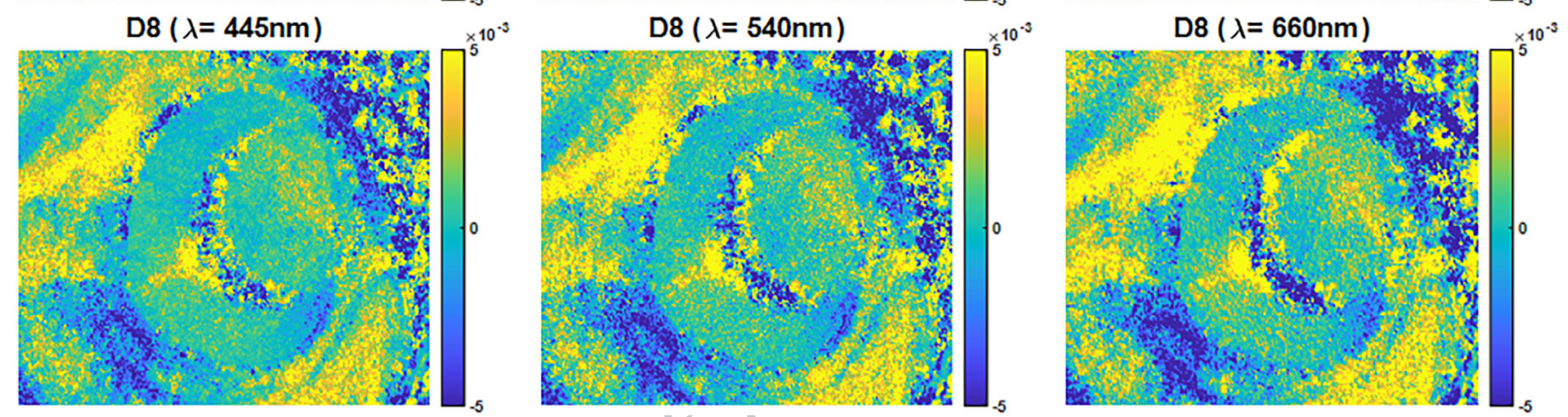

F I G U RE 6 Birefringence image-maps for the three sample groups (control, D2 and D8). Maps are obtained illuminating the eye tissues with three different wavelengths: 445,540 and $660 \mathrm{~nm}$

As shown in our present findings, there is an increased birefringence observed within the lens and retina, these results could agree with those obtained from the previous findings (i.e., the high birefringence observed may be due to increased ECM proteins accumulation in tissues), which might indicate that the method used in the current study could serve as a possible early diagnostic indicator of the cellular and molecular alterations in tissue texture before the use of any molecular labels or stains. Likewise, this also suggests that polarized light imaging can be used as an inexpensive, accurate and rapid technique for detecting microstructural alterations in biological tissues.

It is important to keep in mind that birefringence only changes the incident polarization state; it does not depolarize the light. ${ }^{[30]}$ If we compare the DoCP imagemaps (change in the polarization state of the light) (Figure 5) with the results obtained from the birefringence (Figure 6) we observe that they correspond to each other, in accordance with the general fact that when the linearly polarized light strikes the sample, the points where the DoCP image-maps indicate brighter pixels (higher values of DoCP) will be those in which the light has had phase retardation (retardance) between the two orthogonal linear polarization states.

See how these two maps (Figures 5 and 6) coincide almost perfectly. In general, the results suggest an increase in the birefringence values in both groups, D2 and D8, compared to the control group in which birefringence values are smaller.

As can be seen from Figure 6, the pathologic eyes from D2 and D8 groups showed also high birefringence in choroidal and vitreous regions, both areas are rich in blood vessels. Birefringence also appears in the area corresponding to the ocular musculature and Harder's glands. Previous studies showed that low levels of FA are 

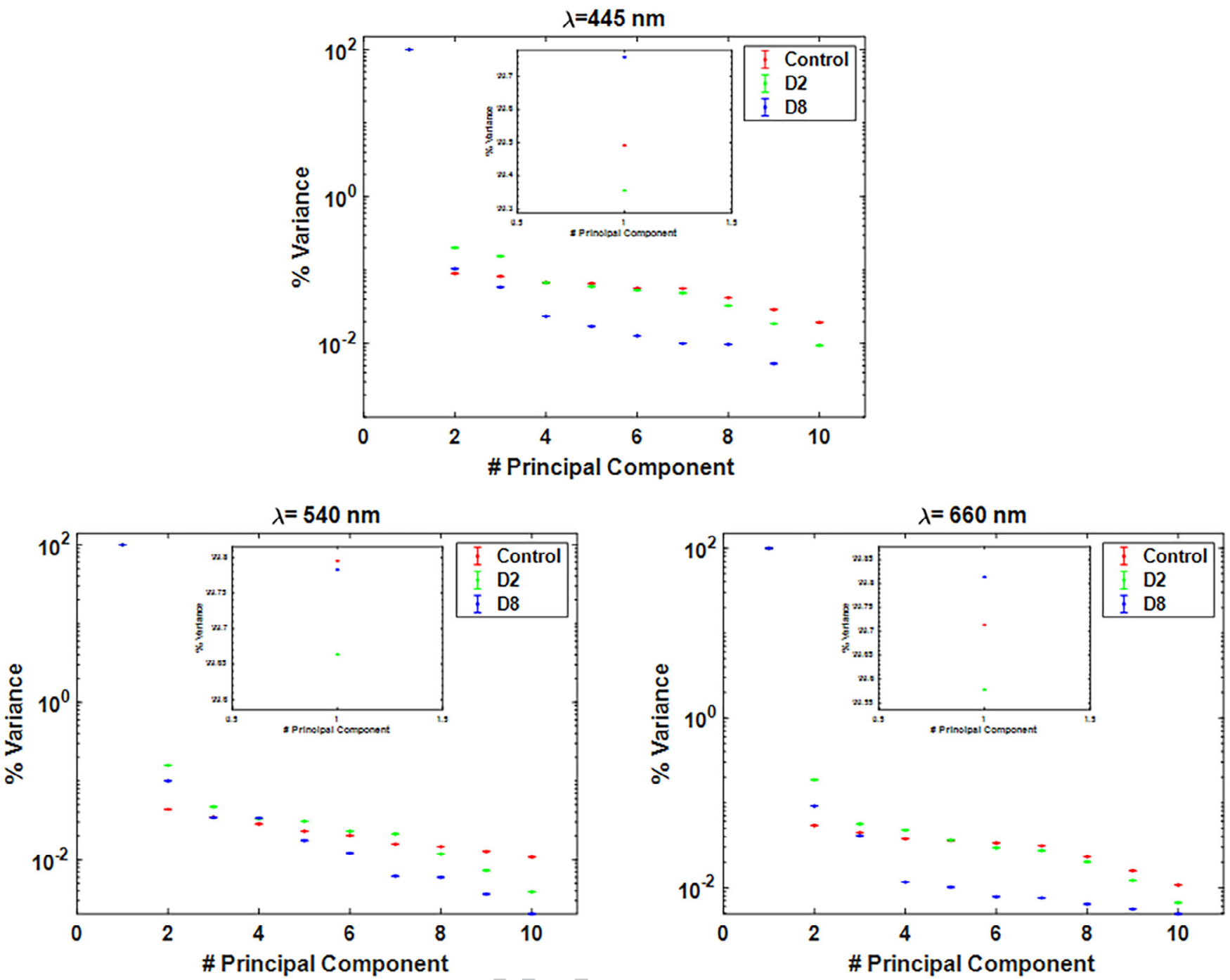

F I G U RE 7 Scree Plot diagram for the eigenvalues of all sample groups (control, D2 and D8) expressed in \% of the variance

associated with ischemia. ${ }^{[31]}$ Under conditions of ischemia-hypoxia, some studies have seen that vascular endothelial growth factor (VEGF) (the major angiogenic factor during development) gene expression increased, ${ }^{[32]}$ inducing the growth of new blood vessels, providing increased transportation of oxygen and nutrients to hypoxic tissue. ${ }^{[33]}$

VEGF overstimulation is known to produce abnormally enlarged blood vessels. ${ }^{[34]}$ At eye level, studies from different groups have reported that overexpressing VEGF released by the retinal pigment epithelium cells results in a thickened choroid with dilated vessels. ${ }^{[35]}$ As well as induces malformed and fused vessels with enlarged lumens. ${ }^{[34]}$ Likewise, hypoxia also seems related to increased expression of angiogenic and inflammatory proteins in the vitreous. ${ }^{[36]}$ Several studies have demonstrated that overexpression of VEGF increases hyaloid vascular area 2-fold compared to wild-type mice. Results suggest that the VEGF promotes an increase in hyalocyte numbers within the hyaloid vessel walls and on the ablumenal surface. ${ }^{[37]}$ All this leads us to think that the vascular pattern in the eyes can be altered during embryonic development if there is not adequate intake of FA during pregnancy.

We must remember that the three wavelengths have practically provided us with the same information. We have not found a great difference between the imagemaps obtained with the different wavelengths. To do this experiment, it would suffice to capture polarization images with a single illuminating wavelength (in our case blue, green or red color).

Once it has been proven that maternal FAD causes birefringence changes in embryonic eye tissues. Let us check now if it also induces optical scattering of tissue. To do this, we will evaluate the DoP increment within the different lenses. The estimation of the DoP increment 
FI G URE 8 Maps of the degree of polarization (DoP) increment for D2 (first column) and D8 (second column) compared to the control group. The red circle indicates possible vacuoles
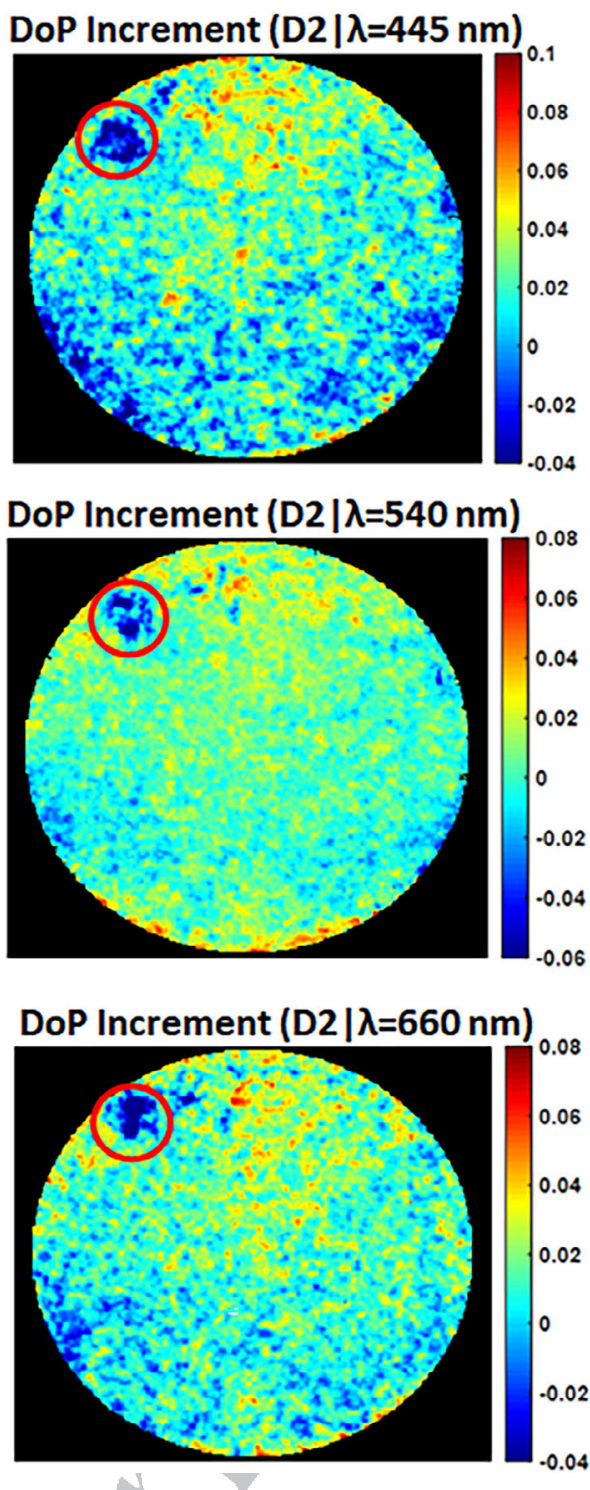
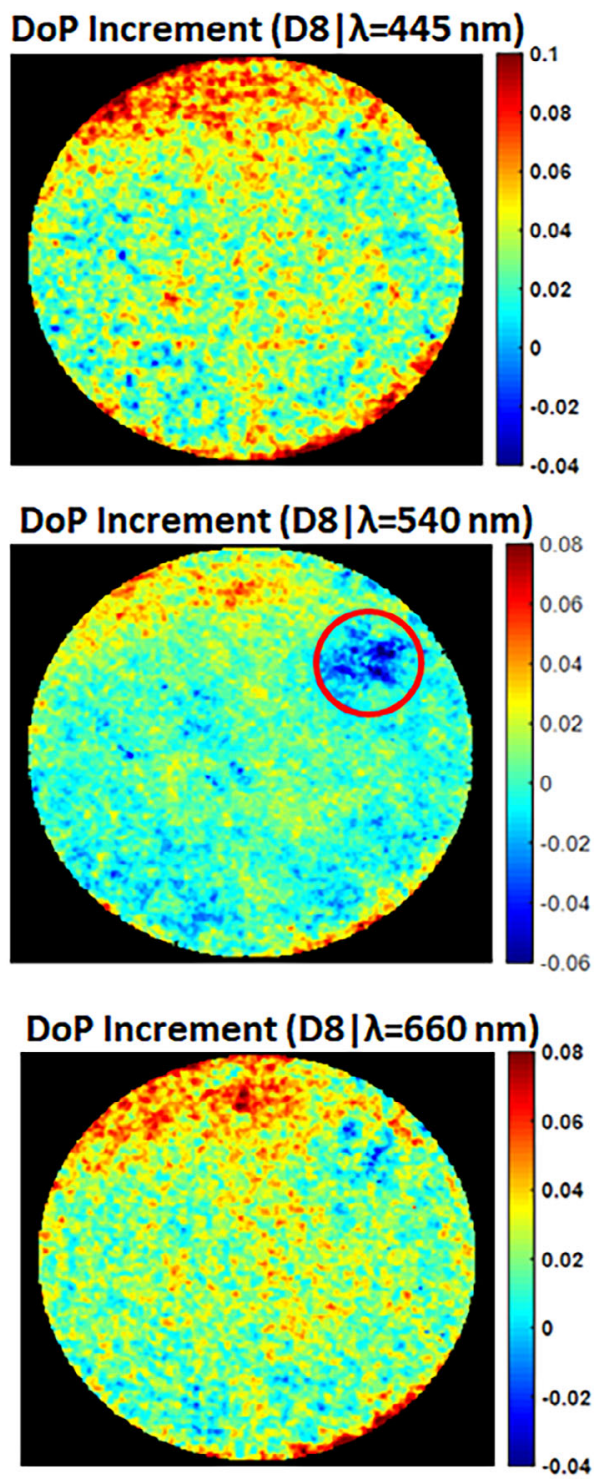

54

is going to be carried out for the three incident wavelengths mentioned above, comparing D2 and D8 with the control group.

First, let us select from each image only the lens. Using Matlab, we apply to each one a circular mask that only leaves us visible the structure of the lens (the final result would be to convert all pixels that are outside the circle to black and only the pixels that are inside the lens would be visible). Subsequently, we will store all lens images of each sample as a single matrix or array. The analysis of these images is carried out using a statistical technique called PCA a data reduction method used to reduce the dimensionality of high-dimensional datasets to a lower-dimensional space using an orthogonal linear transformation while preserving the variance of the data. ${ }^{[38]}$ Due to space constraints, the details of the calculation of the DoP increment using PCA are deferred to the supplementary material.
Figure 7 shows the PCA scree plot for the 3 wavelengths. In all three cases, the first PC comprises $99.5 \%$ of the total variance. While all components from PC \#2 to \#10 add up to $0.5 \%$, those remaining PCs probably represent the noise effect. For this reason, we will evaluate only PC \#1.

The image-maps of the DoP increment for incident light with $\lambda 1=445 \mathrm{~nm}, \lambda 2=540 \mathrm{~nm}$ and $\lambda 3=660 \mathrm{~nm}$ are shown in Figure 8, for D2 (first column) and D8 (second column) with respect to the control group.

This figure clearly shows that both cases have a decrease in the DoP increment, widespread throughout the lens structure (both in its anterior and posterior portions), especially prominent in $\lambda 1=445 \mathrm{~nm}$ for D2 and $\lambda 2=540 \mathrm{~nm}$ for D8. It has been demonstrated that the DoP is affected by an increase in the scattering, ${ }^{[2,39]}$, that is, the DoP decreases as the scattering coefficient increases. 
On the other hand, as shown above, we have also observed a general decrease in DoP in almost all regions of the lens. This may be due to increase in protein aggregates or highly concentrated proteins in lens fiber cells, and it would be compatible with previous findings where we showed an alteration in the expression and arrangement of ECM proteins. ${ }^{[28,29,40,41]}$ It is known that cataractogenesis is caused by light scattering due to random fluctuations in the refractive index. ${ }^{[42]}$ These fluctuations may occur because of differences in the structure of the lens fiber cells involving alterations in the cell membrane, minimal changes in intercellular spacing, changes of structure within the cytoplasm or protein aggregation. $^{[42,43]}$

\section{4 | CONCLUSIONS}

In conclusion, we found that maternal dietary FAD causes modifications in the optical properties of embryonic ocular tissues. By means of this technique, we have been able to detect alterations in the embryos that during their development were deprived of FA. In the case of D8 embryos with prominent alterations, the method applied and described in the present work was effective. It is even more so in the case of D2 embryos, where the malformations, despite being slight, and which might not be detected, the applied method was decisive and conclusive as it revealed the ability to find small alterations in the tissues. In general, our experiment provides valuable information that can be considered as a preliminary observation of the changes produced in the texture of the pathological tissues before proceeding with the appropriate labeling or stains as well as before applying other techniques.

\section{ACKNOWLEDGMENTS}

The following study was supported by grants to the Complutense Research Group 920202 from the Spanish Ministerio de Sanidad (PI06/0184 and PS09/01762). Likewise, it was supported by grants from the Spanish Ministerio de Economia y Competitividad (TEC201340442). Finally, this article was done with a predoctoral fellowship awarded by the Complutense University of Madrid and Banco Santander (reference number CT27/16-CT28/16).

\section{CONFLICT OF INTEREST}

The authors declare no potential conflict of interest.

\section{DATA AVAILABILITY STATEMENT}

Research data are not shared
ORCID

Ouafa Sijilmassi (D) https://orcid.org/0000-0003-0513-0229

\section{REFERENCES}

[1] J. A. Muccini, N. Kollias, S. B. Phillips, R. R. Anderson, A. J. Sober, M. J. Stiller, L. A. Drake, J. Am. Acad. Dermatol. 1995, 33, 765.

[2] V. V. Tuchin, L. Wang, D. A. Zimnyakov, Optical Polarization in Biomedical Applications, Springer Science \& Business Media, 2006.

[3] V. V. Tuchin, J. Biomed. Opt. 2016, 21.

[4] P. J. Wu, J. T. Walsh, J. Biomed. Opt. 2006, 11, 014031.

[5] E. Hecht, Optics, Addison-Wesley, 2002.

[6] M. V. S. R. Group, The lancet 1991, 338, 131.

[7] Y. López-Gordillo, E. Maldonado, L. Nogales, A. Del Río, M. C. Barrio, J. Murillo, E. Martínez-Sanz, I. Paradas-Lara, M. I. Alonso, T. Partearroyo, Pediatr. Res. 2019, 85, 566.

[8] E. Maldonado, Y. López, M. Herrera, E. Martínez-Sanz, C. Martínez-Álvarez, J. Pérez-Miguelsanz, Annals of AnatomyAnatomischer Anzeiger 2018, 218, 59.

[9] O. Sijilmassi, Graefes Arch. Clin. Exp. Ophthalmol. 2019, 257, 1573.

[10] H. H. Wu, S. M. Jovonovich, M. Randolph, K. M. Post, J. D. Sen, K. Curless, L. Cheng, Arch. Pathol. Lab. Med. 2016, 140, 1383.

[11] B. M. Jennings, M. G. Farquhar, H. D. Moon, Am. J. Pathol. 1959, 35, 991.

[12] L. C. Armiger, E. E. Wheeler, D. E. Geraghty, P. B. Herdson, Pathology 1977, 9, 161.

[13] S. D. Jayasingam, M. Citartan, T. H. Thang, A. A. M. Zin, K. C. Ang, E. S. Ch'ng, Front. Oncol. 2019, 9.

[14] P. Arun Gopinathan, G. Kokila, M. Jyothi, C. Ananjan, L. Pradeep, S. Humaira Nazir, Scientifica 2015, 2015, 1.

[15] M. Borovkova, A. Bykov, A. Popov, J. Pahnke, I. Meglinski, Frontiers in Optics, Vol. JTu4A, Optical Society of America, 2019, p. 2.

[16] A. Jain, A. K. Maurya, L. Ulrich, M. Jaeger, R. M. Rossi, A. Neels, P. Schucht, A. Dommann, M. Frenz, H. G. Akarçay, Opt. Express 2020, 28, 16673.

[17] W. S. Bickel, W. M. Bailey, Am. J. Phys. 1985, 53, 468.

[18] E. Collett, Marcel Dekker, Inc. New York. 1993.

[19] N. Mazumder, C.-W. Hu, J. Qiu, M. R. Foreman, C. M. Romero, P. Török, F.-J. Kao, Methods 2014, 66, 237.

[20] M. MATLAB, Version R2018b, Natick, MA: The MathWorks. INC. USA 2018.

[21] E. Maldonado, J. Murillo, C. Barrio, A. del Rio, J. PerezMiguelsanz, Y. Lopez-Gordillo, T. Partearroyo, I. Paradas, C. Maestro, E. Martinez-Sanz, G. Varela-Moreiras, C. MartinezAlvarez, Cells Tissues Organs 2011, 194, 406.

[22] M. Bass, DeCusatis, C., Enoch, J., Lakshminarayanan, V., Li, G., MacDonald, C.A., Mahajan, V., Van Stryland, E, 3rd, McGraw-Hill Professional, New York 2010, 22.21-22.37.

[23] A. A. Kishen A, Series on Biomaterials and Bioengineering, Vol. 4, Imperial College Press, London 2007.

[24] Y. Xiong, Y. Sui, S. Zhang, X. J. Zhou, S. Yang, Y. Fan, Q. Zhang, W. Zhu, Eur. Radiol. 2019, 29, 1997.

[25] S. Vukmirovic-Popovic, N. Colterjohn, Š. Lhoták, W. Duivenvoorden, F. Orr, G. Singh, Bone 2002, 31, 529. 
[26] S. Alali, K. J. Aitken, A. Schröder, A. Gribble, D. J. Bagli, I. A. Vitkin, Biomed. Opt. Express 2014, 5, 621.

[27] R. M. Kottmann, J. Sharp, K. Owens, P. Salzman, G.-Q. Xiao, R. P. Phipps, P. J. Sime, E. B. Brown, S. W. Perry, Respir. Res. 2015, 16, 61.

[28] O. Sijilmassi, J. M. López-Alonso, M. D. C. Barrio Asensio, A. Del Río Sevilla, Graefes Arch. Clin. Exp. Ophthalmol. 2018, 1.

[29] O. Sijilmassi, L. A. J.M, M. C. B. Asensio, A. D. R. Sevilla, J. Microsc. 2018, 271, 207.

[30] V. Sankaran, J. T. Walsh, D. J. Maitland, J. Biomed. Opt. 2002, 7, 300 .

[31] H. Z. Rahman, M. R. Islam, M. Bhuyian, M. Rana, R. Imam, A. J. M. Salauddin, K. K. Patwary, M. S. Uddin, Bangladesh J. Neurosci. 2012, $28,74$.

[32] H. J. Marti, M. Bernaudin, A. Bellail, H. Schoch, M. Euler, E. Petit, W. Risau, Am. J. Pathol. 2000, 156, 965.

[33] J. C. La Manna, S. I. Harik, Oxygen Transport to Tissue XIX, Springer, 1997, p. 163.

[34] C. J. Drake, J. E. Hungerford, C. D. Little, Annals of the New York Academy of Sciences, Vol. 857 1998, p. 155.

[35] C. Schwesinger, C. Yee, R. M. Rohan, A. M. Joussen, A. Fernandez, T. N. Meyer, V. Poulaki, J. J. Ma, T. M. Redmond, S. Liu, Am. J. Pathol. 2001, 158, 1161.

[36] C. Ehlken, B. Grundel, D. Michels, B. Junker, A. Stahl, G. Schlunck, L. L. Hansen, N. Feltgen, G. Martin, H. T. Agostini, PloS One 2015, 10, e0126859.

[37] C. S. Rutland, C. A. Mitchell, M. Nasir, M. A. Konerding, H. C. Drexler, Mol. Vis. 2007, 13, 47.
[38] I. T. Jolliffe, Principal Component Analysis, Springer-Verlag, 54 New York 2002.

[39] S.-W. Lee, J.-H. Kang, J.-Y. Yoo, M.-S. Kang, J.-T. Oh, B.-M. Kim, J. Biomed. Opt. 2008, 13.

[40] O. Sijilmassi, J.-M. L. Alonso, A. D. R. Sevilla, M. D. C. B. Asensio, Chaos, Solitons \& Fractals 2020, 138, 109885.

[41] O. Sijilmassi, J.-M. L. Alonso, A. D. R. Sevilla, M. D. C. B. Asensio, Chaos, Solitons \& Fractals 2020, 138, 109887.

[42] F. Bettelheim, Phys. Basis Lens Trans. 1985, 265.

[43] G. Benedek, J. Clark, E. Serrallach, C. Young, L. Mengel, T. Sauke, A. Bagg, K. Benedek, Series A, Math. Phys. Sci. 1979, 293, 329.

\section{SUPPORTING INFORMATION}

Additional supporting information may be found online in the Supporting Information section at the end of this article.

How to cite this article: Sijilmassi O, LópezAlonso JM, Sevilla ADR, del Carmen Barrio Asensio M. Development of a polarization imaging method to detect paraffin-embedded pathology tissues before applying other techniques. $J$. Biophotonics. 2020;e202000288. https://doi.org/10. 1002/jbio.202000288 


\section{Graphical Abstract}

The contents of this page will be used as part of the graphical abstract of html only. It will not be published as part of main.

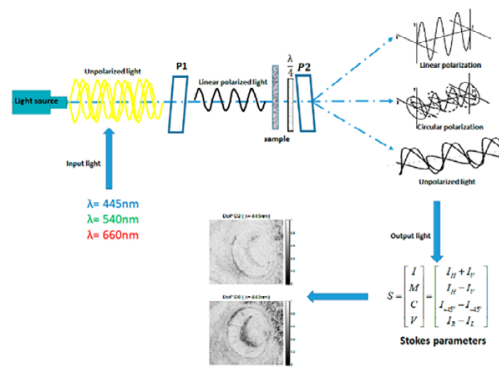

The main target of the present article is to describe a new method for the analysis of section paraffin-embedded tissues prior to applying other biological techniques. The proposed experimental system is based on the measurement of polarization changes in a linearly polarized incident beam by measuring Stokes parameters at three different wavelengths of monochromatic light to view structural damage in embryonic eye tissues due to maternal folic acid deficiency. The degree of light polarization decreases in deficit tissues.

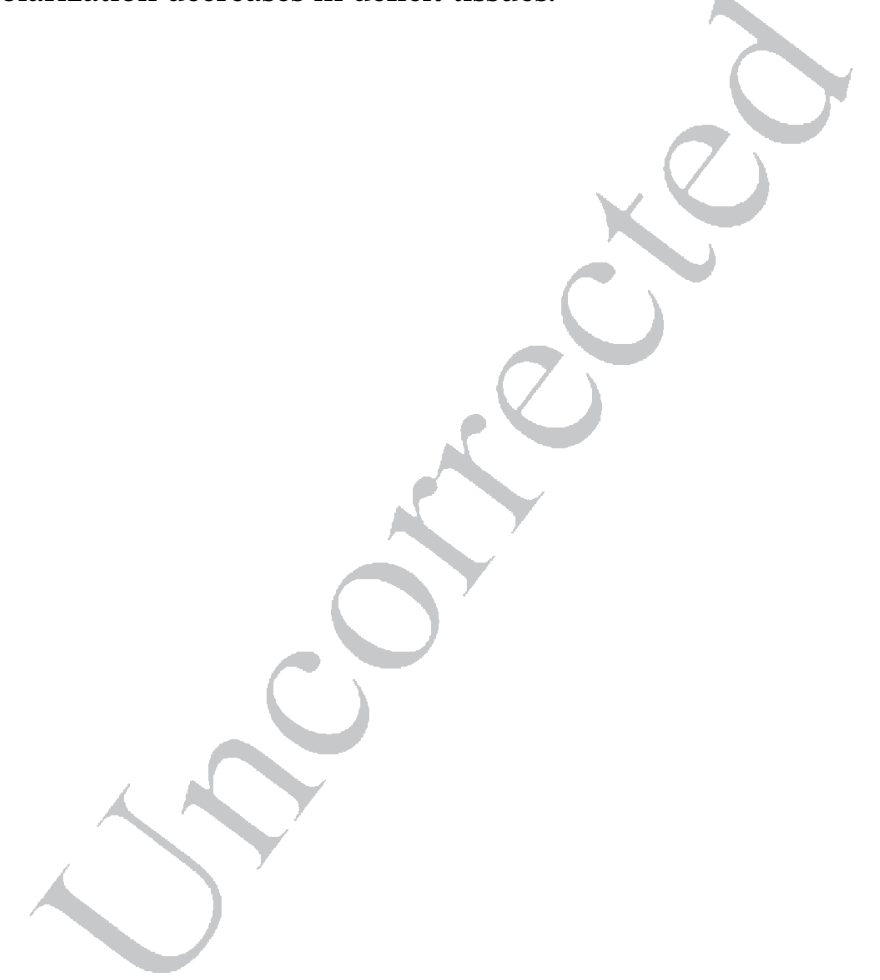

